\title{
Study on Hazard Factor Assessment Caused by Snow Disaster in Pastoral Areas of Inner Mongolia Grassland based on Multi-source Remote Sensing Data
}

\author{
Chula Sa ${ }^{1,2,3}$,Guixiang Liu ${ }^{2, *}$, Mulan Wang ${ }^{1,3}$, Yuhai Bao ${ }^{1,3}$ \\ 1 College of Geographical Science Inner Mongolia Normal University, hohhot 010022, China \\ 2 Grassland Research Institute of Chinese Academy of Agricultural Sciences, hohhot 010010, China \\ 3Inner Mongolia key laboratory of remote sensing and geographic information system, Inner Mongolia \\ Normal University, huhhot 010022, China

\section{基于多源遥感数据的内蒙古草原牧区雪灾致灾 因子危险性评价研究}

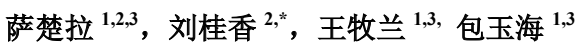 \\ 1 内蒙古师范大学地理科学学院, 呼和浩特 010022 ; \\ 2 中国农业科学院草原研究所, 呼和浩特 010010; \\ 3 内蒙古自治区遥感与地理信息系统重点实验室, 呼和浩特 010022
}

\begin{abstract}
The daily snow depth time series data set from passive microwave remote sensing (1978-2012) were used in this paper. Establishment of snow cover index to evaluate the risk factors of disaster. The areas with highest risk of snow disaster happened were mainly distributed in northeast of Dongwuzhumuqin banner, south of Xinbaerhuzuo banner, western of Chenbaerhu banner and western of Ewenke banner.
\end{abstract}

Keywords: Remote Sensing data ; snow cover day; snow depth; snow disaster

\section{摘要:}

利用中国被动微波遥感逐日雪深长时间序列 数据集 (1978-2012 年) 提取雪深和积雪日数, 建立积雪指标评估了内蒙古草原牧区致灾因 子危险性。内蒙古呼伦贝尔草原和锡林郭勒草 原区的雪灾致灾因子危险性高, 其余地区的危
险性相对低, 其中致灾因子危险性最高的区域 主要分布在东乌珠穆沁旗东北部、新巴尔虎左 旗南部、陈巴尔虎旗西部和鄂温克旗西部。

关键词: 遥感数据; 积雪日数; 雪深; 雪灾

\section{1. 引言}

积雪是地球表层覆盖的重要组成部分, 就全球 和大陆尺度范畴而言, 大范围积雪影响气候变 化、地表辐射平衡与能量交换、水资源利用等; 就局域和流域范畴而言, 积雪影响天气、工农 业和生活用水资源、环境、寒区工程等一系列 与人类活动有关的要素。牧区雪灾风险评价研 究方面, 大量的研究从灾害系统理论出发, 雪 灾的风险是由致灾因子的危险性、承载体的脆 弱性和暴露性的综合作用下形成, 并评价的指 标选取了积雪情况、草情、牲畜灾情以及社会 经济统计资料的指标来开展内蒙古、青海和新 疆等牧区雪灾风险预警与评估研究 (刘兴元等, 2008; 张国胜等, 2009; 张学通, 2010; 何永 


\section{Risk Analysis and Crisis Response in Big Data Era (RAC-16)}

清等, 2010; 王博, 2011; 梁风娟, 2011)。 还有风险评估的单元进行栅格化以及县级行 政区作为基本单位的社会经济属性来反应的 草原牧区雪灾风险评估与风险区划研究 (梁天 刚等, 2004; 伏洋等, 2010; 陈彦清等, 2010)。 尤其在2013年以来,研究区越来越细化到乡镇 为单位, 并研究区扩展到青藏高原以及雪灾综 合风险评估方面研究设计到, 其中多数的研究 区选择了青藏高原地区（李凡等, 2014; 王世 金等,2014; LIU Fenggui, et al,2014), 内蒙古 的积雪面积和雪深监测方面的研究多一些 (萨 楚拉等, 2012, 2013和2015), 但是内蒙古地 区雪灾风险评价研究方面的相对较少。

综合分析已有的对牧区雪灾风险评价所 用的方法和资料发现，所用积雪资料主要来自 气象台站实测数据, 所用的因子有草场面积、 地形、人口和GDP等因子 (李红梅等, 2013), 但是气象站点资料只是点分布数据, 分布不均 匀, 在一个旗县基本上只有一个站点, 不能代 表整个区域积雪的整体状况。在进行雪灾风险 区划时所考虑的因素越多其区划结果可能会 越精确, 但是一般资料不全导致无法进行评估, 实际业务服务中却存在很大的局限性。但是不 管草场面积和地形等因子的情况如何, 由于雪 灾所造成的损失最后的综合表现是牲畜死亡 率以及所造成的直接经济损失的大小。基于以 上分析, 本研究拟采用遥感监测雪深资料中国 区域的雪深长时间序列数据集（1978-2012）、 牲畜死亡数以及直接经济损失对内蒙古草原 牧区进行雪灾风险区划, 有利于雪灾防灾减灾 业务服务中的应用, 也具有一定的科学性。

\section{2. 数据源与数据处理}

\section{1. 资料来源}

网上下载中国西部环境与生态科学数据中心 (http://westdc. westgis. ac. cn)提供的中国被 动微波遥感逐日雪深长时间序列数据集 (1978-2012 年)。该数据集所采用的原始数据 是：从 1978-1987 年的 SMMR、1987-2008 年 的 SSM/I 和 2002-2012 年的 AMSR-E 等被动 微波遥感数据。空间分辨率为 $25 \mathrm{~km}$, 范围为 内蒙古界限，采用全球等积圆柱 EASE-GRID 投影。
地理信息基础数据来源于内蒙古自治区 的 1: 400 万的数据集。

\section{2. 数据处理}

积雪参数定义: 积雪日数指的是遥感影像上各 像元点在一个积雪季节中该像元点积雪类别 出现的日数之和定义为各像元点的积雪日数; 稳定积雪区域是积雪季节里积雪日数在 $60 \mathrm{~d}$ 以上地区定义为稳定积雪区域; 不稳定积雪区 域是积雪季节里积雪日数在小于或等于 $60 \mathrm{~d}$ 的地区定义为不稳定积雪区域; 雪深指的是根 据中国气象局于 2009 年所给出的地面气象观 测规范规定中, 雪深指的是当气象站四周视野 地面被雪覆盖超过一半时要观测雪深, 并平均 雪深不足 $0.5 \mathrm{~cm}$ 的, 记为 $0 \mathrm{~cm}$; 当积雪深度 $\geqslant$ $0.5 \mathrm{~cm}$ 时, 数值四舍五入, 最小值为 $1 \mathrm{~cm}$ 。

数据处理: 首先, 采用ARCGIS软件将原 始雪深数据转化成栅格数据, 然后, 把雪深数 据转换为Albers投影, 进而用内蒙古界限裁剪 生成内蒙古逐日栅格雪深数据, 空间分辨率为 $25 \mathrm{~km}$ 。然后ARCGIS软件中的Raster to Point 模块提取内蒙地区的点数据。利用点专题数据 在ARCGIS软件中的Extract Multi Values to Point模块, 提取每年积雪季的雪深数据。利用 $\mathrm{VC}++6.0$ 语言编程按照积雪参数的定义来统 计积雪季节的积雪参数, 再利用ARCGIS软件 里点数据和统计的积雪参数的Excel表格连接, 并Point to Raster模块得到内蒙古的积雪日数、 初雪日期和终雪日期、雪深等专题地图。

将内蒙古草原牧区的实际情况结合李红 梅等的研究使用了积雪指标来表示某一地区 的致灾危险性大小。积雪指标的定义为某一时 段 $\geqslant 3 \mathrm{~cm}$ 的积雪深度和乘以 $\geqslant 3 \mathrm{~cm}$ 的积雪持续 日数乘积定义为积雪指标。

\section{3. 结果与分析}

\section{1. 积雪日数分析}

雪灾的致灾因子危险性是通过分析发生雪灾 致灾因子过去的活动频次和活动规模（强度） 决定的。一般致灾因子过去活动的规模越大, 活动频次就越高, 雪灾造成的破坏损失就越严 重, 雪灾的风险也越高。因此致灾因子危险性 评估主要是致灾因子的活动频次和活动规模 的评估。雪灾危险性大小评估的指标有很多, 
Risk Analysis and Crisis Response in Big Data Era (RAC-16)

其中最常用的是多年平均积雪日数和平均雪 深来表示。本研究参考了牧区雪灾国家标准和 内蒙古雪灾监测方法研究的雪灾等级气象标 准 (林建等, 2003) 以及结合内蒙古的实际情 况, 在内蒙古草原牧区积雪厚度超过 $3 \mathrm{~cm}$ 且 持续一段时间后，形成雪灾。因此利用上述介 绍的积雪指标进行评估内蒙古草原牧区致灾
因子危险性的高低。我们的雪灾灾情数据都是 年末统计出来的数字, 因此跟灾情数据对应, 本研究计算每年各网格点的 1-3 月和 10-12 月 份的雪深和积雪日数, 并获得每年平均雪深和 积雪日数。图 1 揭示了内蒙古草原牧区 34 年 (1979-2012 年) 平均积雪日数时空分布图。

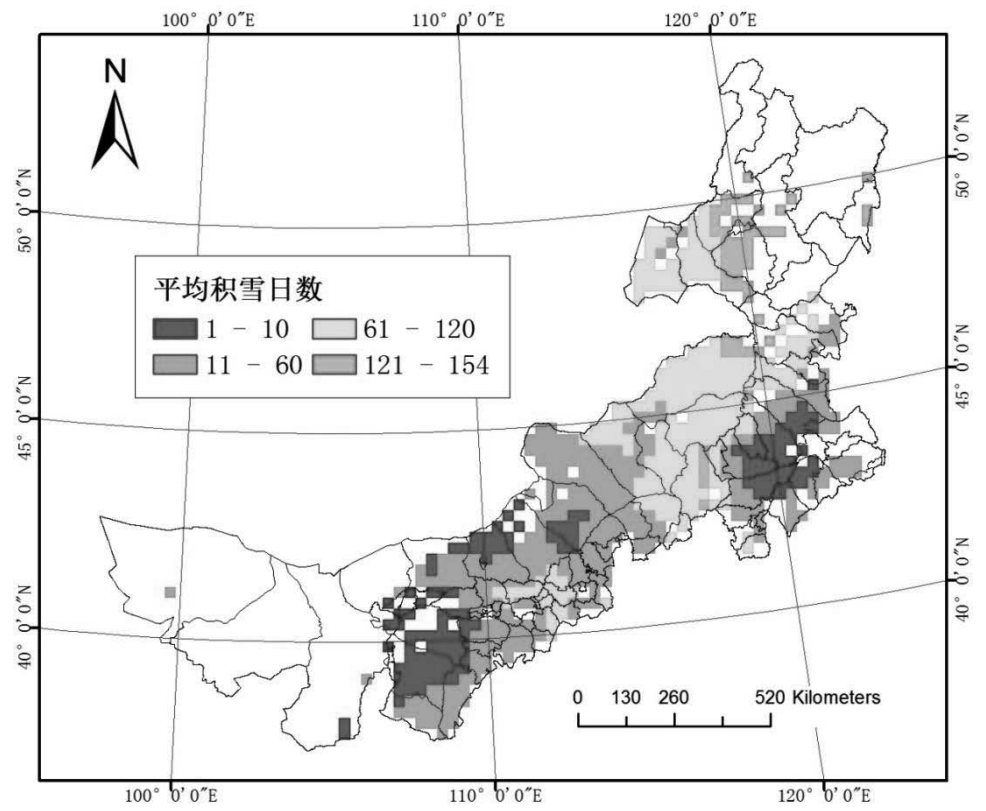

图 1 内蒙古草原牧区 1979-2012 年平均积雪日数时空特征

图1揭示， 60 天以上积雪日数的稳定积雪 区域主要分布在锡林郭勒盟的阿巴嘎旗北部 和南部、正镶白旗东北部、正向蓝旗、多伦县、 锡林浩特市、西乌珠穆沁旗和东乌珠穆沁旗; 呼伦贝尔市的新巴尔虎左旗、新巴尔虎右旗、 鄂温克自治旗、陈巴尔虎旗和海拉尔市; 兴安 盟科右中旗西北部、科右前旗中部和突泉县西 北部; 通辽市扎鲁特旗北部; 赤峰市阿鲁科尔 沁北部、巴林左旗北部、克什克腾旗、林西县 西北部; 乌兰察布市卓资县、凉城县西部和察 哈尔右翼中旗西部; 呼和浩特市的和林县东部、 呼和浩特市区、武川县南部以及包头市固阳县 南部。其中 120 天以上稳定积雪区主要分布在 呼伦贝尔市的新巴尔虎左旗的南部、鄂温克旗
自治旗、海拉尔市区和陈巴尔虎旗中部和东部。

\section{2. 雪灾危险性分析}

图2揭示了内蒙古草原牧区近34年 (1979-2012 年) 的平均雪深空间分布图, 图中积雪深度 $8 \mathrm{~cm}$ 以上区域主要分布在锡林郭勒草原和呼 伦贝尔草原区域。计算各格网点的 34 年的平均 雪深和平均积雪日数后, 按照上述定义的积雪 指标把积雪深度图层乘积雪日数图层后获取 了内蒙古草原牧区雪灾致灾因子危险性大小 分布图3。图中看出, 内蒙古呼伦贝尔草原和 锡林郭勒草原区的雪灾致灾因子危险性高, 其 余地区的危险性相对低, 其中致灾因子危险性 最高的区域主要分布在东乌珠穆沁旗东北部、 
Risk Analysis and Crisis Response in Big Data Era (RAC-16)

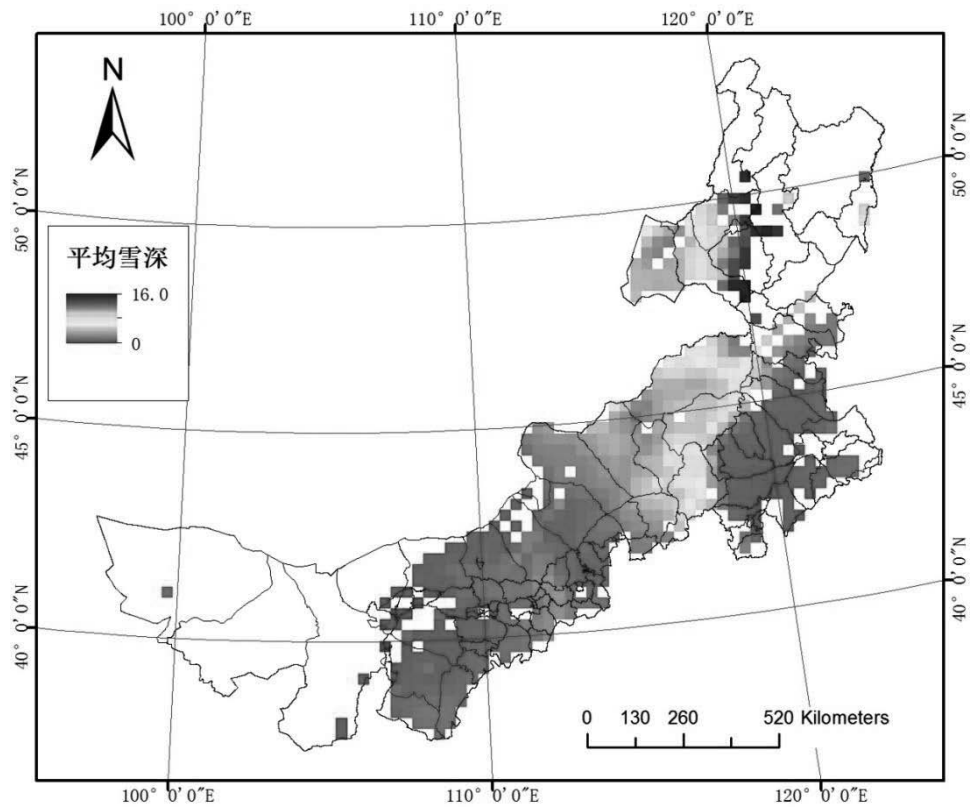

图 2 内蒙古草原牧区 1979-2011 年平均雪深时空特征

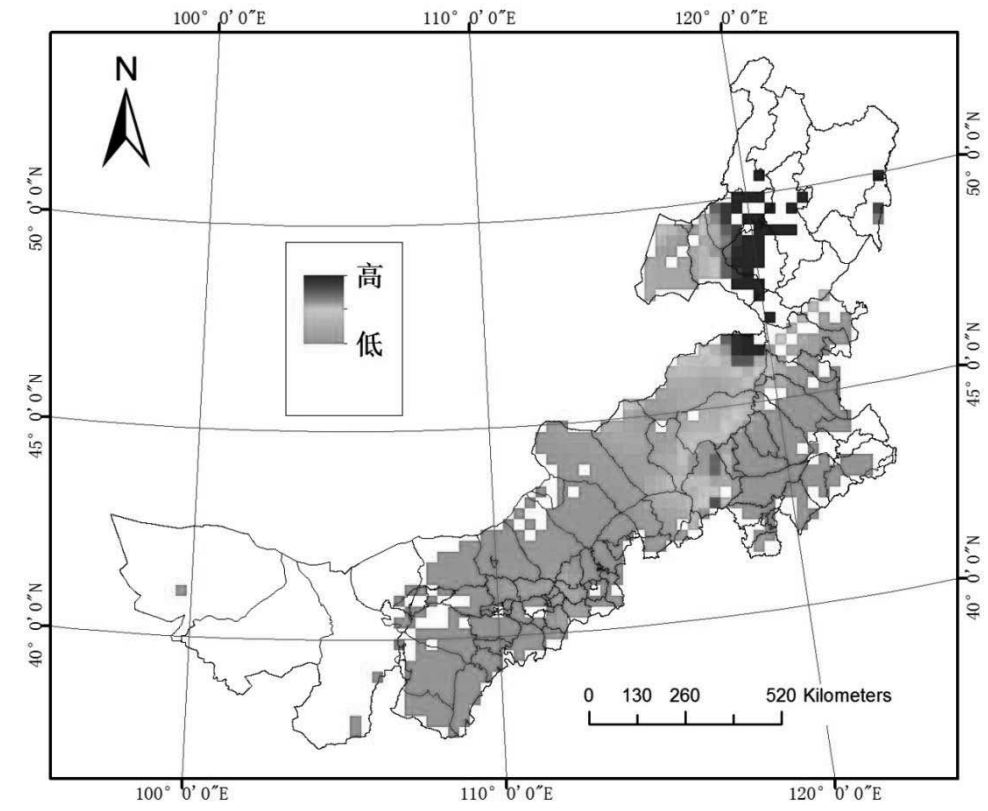

图 3 内蒙古草原牧区致灾因子危险性评估 
新巴尔虎左旗南部、陈巴尔虎旗西部和鄂温克 旗西部。致灾因子危险性分布图是把内蒙古草 原牧区的各旗县划分为 25 公里大小的格网, 并基于遥感的格网数据统计的, 因此比灾情频 率图揭示更详细和清除, 至于乌拉特后旗不属 于草原牧区, 致灾因子危险性分布图里未考虑 非牧区雪灾。

\section{4. 结论与讨论}

以往的长时间序列的内蒙古雪灾致灾因子方 面的研究基本上利用气象站点的数据, 气象站 点资料大多为站点数据, 分布不均匀, 在一个 旗县基本上只有一个站点, 不能代表整个区域 积雪的整体状况。本文利用多源遥感数据, 研 究了长时间序列的内蒙古雪灾致灾因子危险 性评价尚属空白。主要结论如下:

1) 近34年, 内蒙古草原牧区积雪覆盖 120 天以上的稳定积雪区主要分布在呼伦贝尔市 的新巴尔虎左旗的南部、鄂温克旗自治旗、海 拉尔市区和陈巴尔虎旗中部和东部。积雪覆盖 61-120天的稳定积雪区主要分布在锡林郭勒 草原和呼伦贝尔草原区。

2）近 34 年，揭示了内蒙古草原牧区的平 均雪深 $8 \mathrm{~cm}$ 以上区域主要分布在锡林郭勒草 原和呼伦贝尔草原区域。

3）近 34 年, 内蒙古呼伦贝尔草原和锡林 郭勒草原区的雪灾致灾因子危险性高, 其余地 区的危险性相对低, 其中致灾因子危险性最高 的区域主要分布在东乌珠穆沈旗东北部、新巴 尔虎左旗南部、陈巴尔虎旗西部和鄂温克旗西 部。

雪灾风险方面考虑到实际业务中服务, 利 用中国被动微波遥感逐日雪深长时间序列数 据集 (1978-2012年), 建立积雪指标对内蒙古 草原牧区雪灾致灾因子危险性评价, 吻合内蒙 古的实际雪灾风险情况。但是草原牧区的牲畜 的死亡数和直接经济损失不仅雪灾有关系, 还 有夏天的干旱 (旱灾)、冬天的大量的降雪 (雪 灾) 和冬天的持续低温（冰冻灾害）等共同影 响牧区的损失。因此今后的研究当中要考虑旱 灾、雪灾和冰冻灾害的灾害链来分析风险区划。

\section{Acknowledgements}

This study was supported by the Natural Science Foundation of Inner Mongolia (No.2016MS04
09), Inner Mongolia science and technology project (201502095), Innovation team of disaster prevention and mitigation of grassland non biological disasters in Chinese Academy of Agricultural Sciences (CAAS-ASTIP-IGR 20160406) and Inner Mongolia Normal University Project (2015YJRC013).

Corresponding author: Guixiang Liu, Email : liugx804@163.com

\section{致谢}

本研究得到了内蒙古自然科学基金项目 (2016MS0409), 内蒙古科技计划项目 （201502095）, 中国农业科学院草原非生物 灾害防灾减灾创新团队项目

(CAAS-ASTIP-IGR 2016-0406) 和内蒙古师 范大学项目 (2015YJRC013) 的资助。通讯作 者: 刘桂香, Email: liugx804@163.com

\section{参考文献:}

[1] 陈彦清, 杨建宇, 苏伟, 等. 县级尺度下 雪灾风险评价方法. 农业工程学报, 2010, 26(Supp2):307-311.

[2]伏洋, 肖建设, 校瑞香, 等, 赵慧芳. 基于 GIS 的青海省雪灾风险评估模型. 农业工 程学报, 2010, 26(1):197-205.

[3]何永清, 周秉荣, 张海静, 等. 青海高原雪 灾风险度评价模型与风险区划探讨. 草业 科学, 2010, 27(11):37-42.

[4] 梁风娟, 孟雪峰, 王永清, 孙令东, 吕娜, 吴国 周等.基于 GIS 的雪灾风险区划. 气象科 技,2014,42(2):336-340

[5]梁风娟. 基于 GIS 的巴彦淖尔市雪灾风险 区划 [C]//第 28 届中国气象学会年会. 北 京:中国气象学会, 2011.

[6]刘兴元, 梁天刚, 郭正刚, 等. 北疆牧区雪 灾预警与风险评估方法. 应用生态学报, 2008, 19(1): 133 - 138 .

[7]梁天刚, 高新华, 刘兴元. 阿勒泰地区雪灾 遥感监测模型与评价方法. 应用生态学报, 2004, 15(12):2272-2276.

[8]李红梅,李林,高歌,刘义花等.青海高原雪灾 风险区划及对策建议.冰川冻 土,2013,35(3):656-661

[9]李凡, 侯光良, 鄂崇毅, 刘钊, 姜莹莹, 席 永帅等. 基于乡镇单元的青海高原果洛地 
Risk Analysis and Crisis Response in Big Data Era (RAC-16)

区雪灾致灾风险评估. 自然灾害学 报,2014,23(6):141-148

[10]LIU Fenggui, MAO Xufeng1, ZHANG Yili, CHEN Qiong, LIU Pei, ZHAO Zhilong. Risk analysis of snow disaster in the pastoral areas of the Qinghai-Tibet Plateau. Journal of Geographical Sciences, 2014,24(3):411-426

[11]萨楚拉, 刘桂香, 包刚等.内蒙古积雪面积 时空变化及其对气候响应.干旱区资源与环 境,2013，27 (2): 137-142

[12]萨楚拉, 刘桂香, 包刚等.近 10 年蒙古高 原积雪面积时空变化研究.内蒙古师范大学 学报 (自然科学汉文版), 2012, 41 (5): 531-536

[13]萨楚拉, 王牧兰等.基于风云 $3 \mathrm{~B}$ 微波亮温 数据的内蒙古草原牧区雪深反演研究.中国 草地学报, 2015, 37（3）:60-66

[14]王世金,魏彦强,方苗.青海省三江源牧区雪 灾综合风险评估.草业学报, 2014,23(2): 108-116

[15]王建刚,王盛蹈,庄晓翠, 郭城,巴合提 - 斯哈 克.新疆北部雪灾气候因子的风险分析试验 - 以阿勒泰为例。气象科技,2014,42(2): 330-335

[16]王博. 内蒙古锡林郭勒盟牧区雪灾气象因 子灰色关联分析与评估模型研究 [D]. 北 京:首都师范大学, 2011 .

[17]张学通. 青海省积雪监测与青南牧区雪灾 预警研究 [D]. 兰州:兰州大学, 2010 .

[18]张国胜, 伏洋, 颜亮东, 等. 三江源地区 雪灾风险预警指标体系及风险管理研 究. 草业科学, 2009, 26 (5): 144- 150 .

[19]Zhuo Yi, Liu Guixiang, Yu Fengming. The Combustible Materials Remote Sensing Ration Calculation and Fire Risk Dynamic Monitor in the Seasons of Withered Grass in Xilingoule Grassland. Journal of Risk Analysis and Crisis Response, 2011,1(1): 65-74

[20] Xiaomei Guo, Xiaobing Hu, Hang Li, Zhen Xu. A Study on Spatial-Temporal Rainstorm Risk at Civil Airports in China. Journal of Risk Analysis and Crisis Response, 2015,5(3) :188-198 